\title{
Constraints in Using Manufactured Sands in Concrete Pavements in Australia
}

\author{
Ion Dumitru ${ }^{1}$, Tony Song ${ }^{1}$, Bob Bornstein ${ }^{1}$ and Vute Sirivivatnanon ${ }^{2}$ \\ 1. Materials Technical Services Department, Boral Resources (New South Wales) Pty Ltd., New South Wales 2153, Australia \\ 2. School of Computing, Engineering and Mathematics, University of Western Sydney, New South Wales 2751, Australia
}

\begin{abstract}
Due to the shortages of natural sands along the east coast of Australia in particular and the need to fully utilise fines produced in quarry operations, progress has been made in utilising blends of manufactured sands and natural sands in concrete pavements. This paper documents some of the constraints in utilising larger proportions of manufactured sands in concrete pavements. These constraints are mainly caused by the current level of knowledge regarding the impact of manufactured sands on skid and abrasion resistance of concrete pavements. This paper presents a brief review of literature on this subject in the USA, France and UK. It also briefly documents work recently carried out in Australia by CCAA (Cement Concrete and Aggregates Australia), referring to the skid and abrasion resistance of concrete pavements using manufactured sands. The paper concludes that there is no relationship between the free silica content and the skid resistance. With regard to the abrasion resistance, it is rather the curing conditions and the compressive strength that are more important in achieving good results.
\end{abstract}

Key words: Manufactured sand, concrete pavements, skid resistance, abrasion resistance, free silica content.

\section{Introduction}

Shortages of good quality natural sands for concrete production are becoming more prevalent in Australian eastern states, mainly Victoria, New South Wales and Queensland. The shortages of good quality natural sands combined with the imperative need to better utilise quarry dust produced in quarry operations (for a long time considered as a waste product) have resulted in significant progress in utilization of manufactured sands in concrete.

A CCAA (Cement Concrete and Aggregates Australia) subcommittee established in 2004 has carried out extensive research, resulting in recommendation for national test methods and limit specifications for manufactured sand [1].

Although significant progress was evident in the area of manufactured sands in concrete, the road authorities in Australia were reluctant to allow a large

Corresponding author: Tony Song, senior development engineer, research fields: concrete durability and maturity, self-compacting concrete, sustainable concretes and geopolymer concrete. E-mail: tony.song@boral.com.au. amount of manufactured sands in concrete road pavements, limiting the percentages of manufactured sands in concrete at no more than $50 \%$ and requiring high percentages of silica in natural sands to be blended with manufactured sands. The limited percentage of less than $50 \%$ of manufactured sands was due to the lack of data on the manufactured sand effects on skid and abrasion resistance. From 2010 to 2012, CCAA have done comprehensive studies regarding the manufactured sand in pavement concrete $[2,3]$.

\section{Constrains in Using Larger Amount of Manufactured Sands in Concrete Pavements}

Two major problems have restricted the usage of larger amount of manufactured sands in concrete pavements:

(1) The requirement of minimum $50 \%$ by mass natural sand is used in a blend with manufactured sands in a concrete pavement [4];

(2) The requirement of minimum $70 \%$ of quartz or chert in natural sands [4] is used with the view to 
ensure higher skid resistance to the slip formed concrete base. It appears that the support behind the minimum $70 \%$ quartz content in natural sands came from the British Road Research Laboratory Report LR334 [5], which highlights that "the use of high silica content natural sands always yielded higher skid resistance values than did relatively soft sands or crushed fine materials".

\subsection{Silica Content in Natural Sands-Studies in USA}

The guidelines for skid resistance pavement design [6] stated that four factors are to be considered in order to achieve better wear resistance on the concrete pavement surface:

(1) Wear resistance of concrete increases as cement factor is increased;

(2) Wear resistance of concrete increases as the water/cement ratio is decreased;

(3) To provide a good skid resistance, the proportion of fine aggregates in the concrete mix should be "near the upper limit of the range" that permits proper placing, finishing and texturing. The silicious particle content of the fine aggregate "should be not less than $25 \%$ ";

(4)The concrete durability and wear resistance are influenced by the effectiveness of curing.

According to NCHRP Project 01-43 [7], the following issues were considered:

- Aggregate properties with significant influence in concrete pavement friction performance are hardness and mineralogy;

- Concrete made with aggregates made up of hard minerals only, typically achieve good wear resistance but will polish quickly under traffic;

- Concrete made with aggregates that are moderately soft, achieve good polishing but will wear quickly under traffic;

- A wear resistant aggregate is necessary in the mix, but some wearing of the surface is necessary in achieving proper skid resistance;

- The polishing resistance of fine aggregates is the most critical parameter.

What the document in fact is saying is that a blend of hard and high resistant wear aggregates with moderately softer aggregates is the best outcome in achieving a good wear resistant and skid resistant concrete pavement. Furthermore, the document also highlights the importance of proper curing, in order to achieve good durability and skid resistance.

\subsection{Silica Content in Natural Sands-Studies in} France

An important document about the surface characteristics of concrete pavements [8] concluded that:

- The in-depth treatment of fresh concrete provides good skid resistance;

- Macro roughness must be designed as early as the construction of the pavement;

- During the pavement construction, anything which may reduce the strength of the surface should be avoided;

- Effective curing products should be spread correctly.

The document did not refer to limits for silica content in fine aggregates.

\subsection{Silica Content in Natural Sands-Studies in UK}

Work was carried out by the Ministry of Transport (RRL Report LR334 [5] and LR335 [9]) has concluded that:

- The most important constituents in a concrete pavement mix are the fine aggregates in order to achieve good skid resistance;

- The harder sands generally exhibit, the better skid resistance would be at the end of a dry wearing stage;

- During the period of wet polishing, the skid resistance of mortars made with harder sands decreases and the mortars made with softer sands exhibit an increased skid resistance;

- Based on several types of fine aggregates used in 
the research, the document concluded that the use of high silica content natural sands always yielded higher skid resistance value than did relatively soft sands or crushed fine materials.

It is important to note that there are no limits suggested for silica content in the fine aggregates. The conclusion drawn on silica content can be easily explained, considering the type of fine aggregates used in the trial mixes (flint gravel, dolomitic limestone, soft dolerite and gritstone). However, there is no explanation why calcinated bauxite with no high percentage silica "was always superior to any sand".

\subsection{Silica Content in Natural Sands-Studies in Australia}

In a recent study by CCAA [2], three natural sands and nine manufactured sands were selected to make concrete for the skid resistance. Three natural sands have the free silica content exceeding $83 \%$ while five of nine manufactured sands have less free silica content of between $61 \sim 69 \%$. The skid resistance test was performed at a period of $4 \mathrm{~h}$ and extended to another $4 \mathrm{~h}$. It was noticed that the skid resistance of concrete with those five manufactured sands were very similar or even higher in comparison with all concretes with three natural sands. The skid resistance after $8 \mathrm{~h}$ of polishing indicated that the use of sand with low and high free silica content does not necessarily lead to concrete with high skid resistance from a long term of polishing action. Based on this study, there is no support that sand with high free silica content will result in concrete with higher skid resistance.

3. Aggregate Properties with Significant Influence on Pavement Friction Performance

As noted previously, the following issues must be considered: (1) Aggregates made up only with hard minerals resist wear but may polish easily under traffic; (2) Aggregates made up only with softer minerals achieve good skid resistance but wear easily under traffic; (3) A blend of wear resistant aggregate and soft mineral aggregates are ideal in ensuring that some wearing of the concrete surface occur, resulting in higher skid resistance as a new micro texture. Fine aggregates, with angular edges and cubical or irregular shape, provide higher level of microtexture (Fig. 1) with rounded edges or elongated shape aggregates exhibiting lower micro texture; (4) Aggregate properties, with significant influence on pavement friction performance, are hardness and mineralogy.

With regard to rock hardness and mineralogy, it is necessary to note that, according to Mohs scale, minerals are classified as:

\section{Hardness $>6$ \\ Softness: $3 \sim 5$}

Considering Mohs scale (Fig. 2) and the requirements of minimum $70 \%$ quartz in natural sands [4], it is obvious that: (1) Natural sands, containing minerals with hardness higher than 7 (quartz), are to be considered unsuitable in concrete pavements, if the quartz levels is not minimum $70 \%$; (2) Natural sands, containing minerals with hardness equal or higher than 6 , are to be also considered unsuitable in concrete pavements, if the quartz level is not minimum $70 \%$.

This is a matter of concern for the industry and steps are being implemented to address the issue.

\section{Other Appropriate Tests to Be Considered}

\subsection{MBV (Methylene Blue Value)}

Grading, particle size distribution, shape and surface

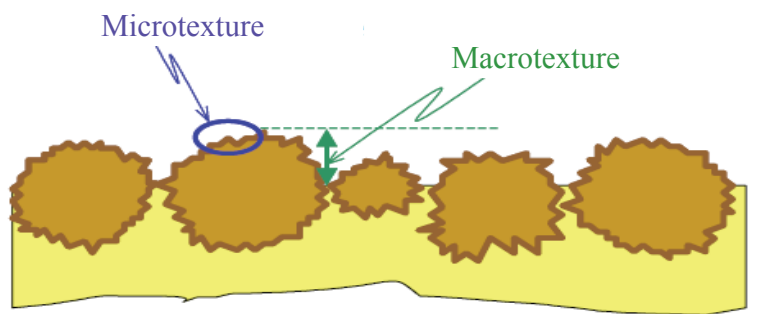

Fig. 1 Microtexture and macrotexture [10]. 


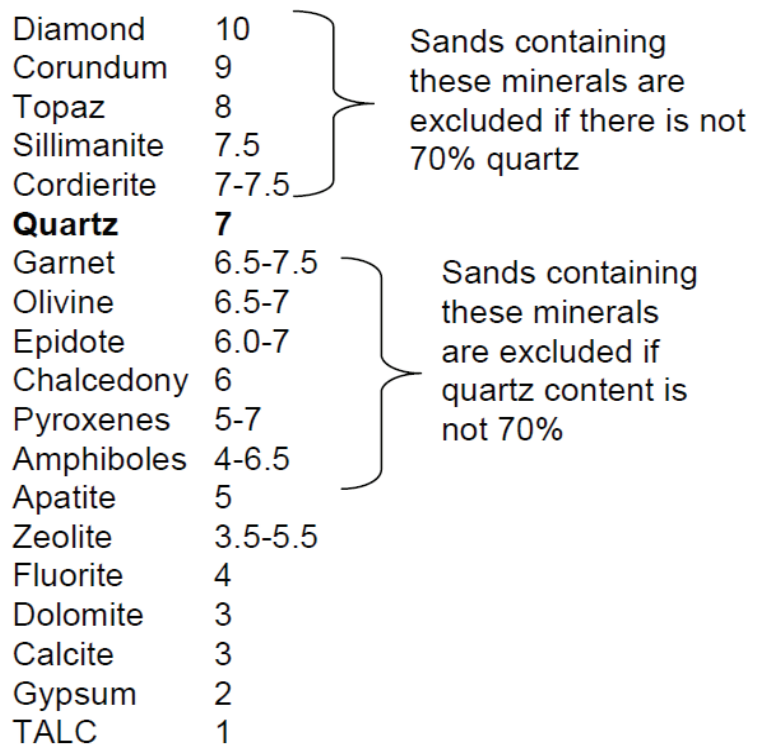

Fig. 2 Mohs scale (hardness) [11].

texture, durability tests, chlorides and sulphates and so on were properly considered in the CCAA T60 document [1].

It is well known that the type of microfines in fine aggregates has influenced the water demand of a concrete pavement mix manufactured with such microfines. Methylene blue dye absorption has been used widely as a means of determining and specifying the presence of clay minerals in aggregates. This research used the procedure defined in the ISSA's (International Spray Seal Association) Technical Bulletin 145. The MBV (methylene blue value) is a valuable parameter in identifying the potential for active clays in microfines. In addition, the $75 \mu \mathrm{m}$ in aggregates can be determined by washing as per AS 1141.11 [12]. The CCAA T60 document [1] recommended that a manufactured sand is suitable to be used in concrete, providing it meets Eq. (1)":

MBV $\times$ Percentage $(\%)$ passing of $75 \mu \mathrm{m}<100$

It is important to note that the MBV results may be influenced by a few factors [13]:

- wet or dry sieving;

- particle size of the sample tested;

- type of clay present in the microfines.

Clay minerals are almost always present in the weathering processes. Kaolinite is a low or non reactive clay, while the bentonite clays are reactive. It clearly shows in Table 1 that the bentonite clays are reactive, the results being more than double when $5 \%$ of bentonite was added to the tested sample. By contrast, a level of up to $10 \%$ of kaolinite added to the tested sample did not show any increase of the MBV results.

Some effects on dry and wet sieving on MBV results are presented in Table 2. When $-75 \mu \mathrm{m}$ fraction was tested, all wet sieving samples results were higher than the dry sieving samples. However, when the $-75 \sim+45-\mu \mathrm{m}$ fraction was tested, the wet sieving samples had lower MBV results.

Table 1 Effects of type of clay on MBV results.

\begin{tabular}{|c|c|c|c|}
\hline \multirow{2}{*}{ Fraction tested } & \multirow{2}{*}{$\begin{array}{l}\text { Percentage (\%) of clay } \\
\text { introduced }\end{array}$} & \multicolumn{2}{|c|}{ MBV (ISSA test method) (mg/g) } \\
\hline & & Bentonite & Kaolinite \\
\hline \multirow{5}{*}{$-75 \mu \mathrm{m}$} & 0 & 10.0 & 10.0 \\
\hline & 1.0 & 11.0 & - \\
\hline & 2.5 & 16.0 & - \\
\hline & 5.0 & 21.0 & 10.0 \\
\hline & 10.0 & - & 10.5 \\
\hline \multirow{5}{*}{$-75 \sim+45 \mu \mathrm{m}$} & 0 & 6.5 & 6.5 \\
\hline & 1.0 & 9.5 & - \\
\hline & 2.5 & 13.0 & - \\
\hline & 5.0 & 17.0 & 7.0 \\
\hline & 10.0 & - & 7.5 \\
\hline \multirow{5}{*}{$<45 \mu \mathrm{m}$} & 0 & 10.5 & 10.5 \\
\hline & 1.0 & 13.0 & - \\
\hline & 2.5 & 15.5 & - \\
\hline & 5.0 & 20.5 & 10.0 \\
\hline & 10.0 & - & 10.5 \\
\hline
\end{tabular}


Table 2 Effects of dry and wet sieving on MBV results.

\begin{tabular}{|c|c|c|c|}
\hline \multirow{2}{*}{ Fraction tested } & \multirow{2}{*}{$\begin{array}{l}\text { Type and percentage (\%) of clay added to the original } \\
\text { sample }\end{array}$} & \multicolumn{2}{|c|}{ MBV (ISSA test method) (mg/g) } \\
\hline & & Dry sieving & Wet sieving \\
\hline$-75 \mu \mathrm{m}$ & 0 & 10.0 & 14.5 \\
\hline$-75 \sim+45 \mu \mathrm{m}$ & 0 & 6.5 & 2.0 \\
\hline \multicolumn{4}{|l|}{ Bentonite } \\
\hline \multirow{3}{*}{$-75 \mu \mathrm{m}$} & 1.0 & 11.0 & 17.0 \\
\hline & 2.5 & 16.0 & 18.5 \\
\hline & 5.0 & 21.0 & 25.5 \\
\hline \multirow{3}{*}{$-75 \sim+45 \mu \mathrm{m}$} & 1.0 & 9.5 & 5.0 \\
\hline & 2.5 & 13.0 & 7.5 \\
\hline & 5.0 & 17.0 & 13.0 \\
\hline \multicolumn{4}{|l|}{ Kaolinite } \\
\hline \multirow{2}{*}{$-75 \mu \mathrm{m}$} & 5.0 & 10.0 & 14.5 \\
\hline & 10.0 & 10.5 & 14.5 \\
\hline \multirow{2}{*}{$-75 \sim+45 \mu \mathrm{m}$} & 5.0 & 7.0 & 3.0 \\
\hline & 10.0 & 7.5 & 4.0 \\
\hline
\end{tabular}

\subsection{Micro Deval}

Current durability test methods in Australia, for both natural and manufactured sands (i.e., sodium sulphate soundness, sand equivalent and degradation factor), are not able to determine the resistance to wear or the results are difficult to correlate. In fact, NCHRP report [7] has considered magnesium sulphate soundness as being more consistent than sodium sulphate from results point of view, recommending a loss of $<10 \%$ after five cycles.

Work carried out by CCAA has identified Micro Deval test as a good option to evaluate the relationship between the Micro Deval value and the skid resistance [3]. It was concluded that there is a reasonable good relationship between the skid resistance and the Micro Deval loss, with a clear reduction of skid resistance with increasing percentage loss of Micro Deval value (Fig. 3), while a Micro Deval value figure of $15 \%$ would be considered to be specified as an upper limit.

It is interesting to note that a similar correlation has been established in the USA [14], concluding that, using an AI (Acidity Index) of $60 \%$ or a Micro Deval percent loss of $12 \%$, good skid resistance concrete pavement could be achieved.

The differences between the proposed Micro Deval value limits, the study in Australia and the study in the
USA, are due to differences in type of equipment used for skid resistance and in particular due to the types of used fine aggregates. In USA, carbonaceous aggregates have been largely considered, but not such fine aggregates were used in concrete trial mixes in the study carried out in Australia.

It is important to note that, recently, the Transport Authority in New South Wales has made major changes in the specification for concrete pavement, allowing unlimited amount of manufactured sand,

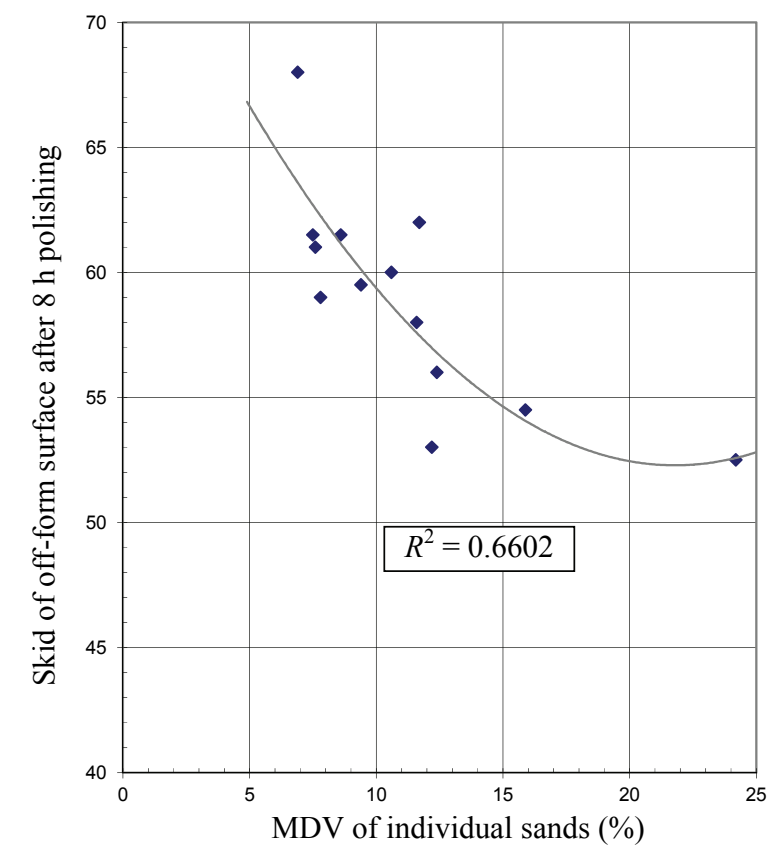

Fig. 3 Relationship between Micro Deval value and skid resistance. 
dropping the free silica content request and adopting Micro Deval as a major durability assessment of manufactured sand.

In Japan, a study was carried out on durability of micro fines [15], aiming at the effective use of dry micro fines when producing well-shaped manufactured sand using a dry process. The study has concluded that the exclusion of particles less than $40 \mu \mathrm{m}$ will prevent the increase of water demand in concrete mixes, and three durability tests (accelerated neutralisation, water permeability and freeze-thaw) were considered to assess manufactured sands durability.

\subsection{Two Microns (2 $\mu \mathrm{m})$}

The current limit for two micron fractions is less than $1 \%$ in the sand samples, which have at least $4 \%$ passing $75-\mu \mathrm{m}$ fractions.

The results are, in general, affected by the density of the solids in suspension and also overestimated if montmorillonite (an expansive clay) is present, or they are underestimated if kaolinite (a non-expansive clay) is present.

The test does not pick up the expansive or non-expansive clay, and it is necessary that the type of clay is to be determined if the two microns is higher than $1 \%$. Studies [16] have demonstrated that:

(1) Up to $3 \sim 4 \%$ kaolinite (non-expansive clay) introduced in a concrete mix results in:

- high compressive strength;

- lower drying shrinkage;

- lower permeability;

- lower chloride diffusion;

(2) Up to $1 \sim 2 \%$ bentonite (expansive clay) in a concrete mix resulted in lower compressive strength, drying shrinkage, permeability and chloride diffusion.

\section{Conclusions}

Discussions between industry and transport authorities should continue in order to address several current constraints in using manufactured sands in concrete pavement mixes.

These constraints refer to:

- minimum percentage of natural sands in blends with manufactured sands;

- percentage of quartz in natural sands;

- issues related to some of the conditions that may influence the MBV results;

- the two micron limits in manufactured and natural sands and the need to determine the type of clay present.

Some laboratory tests are recommended:

- The critical property of fine aggregates in concrete pavements is the durability by Micro Deval test which has reasonably good relationship with skid resistance. The Micro Deval value should be considered as a performance based specification;

- Other essential properties for fine aggregates in concrete pavement include shape, surface texture and, in particular, consistent particle size distribution;

- There is no correlation between the free silica content of sand and the skid resistance of concrete with such sand.

\section{Acknowledgments}

The authors gratefully acknowledge the support of Boral Materials Technical Services and approval to publish this paper. The opinions expressed in this paper are entirely those of the authors and not necessarily the policies and practices of the organizations they represent.

\section{References}

[1] CCAA (Cement Concrete and Aggregates Australia). 2008. Guide to the Specification and Use of Manufactured Sand in Concrete, CCAA T60. New South Wales: CCAA.

[2] CCAA (Cement Concrete and Aggregates Australia). 2012. Effect of Manufactured Sand on Surface Properties of Concrete Pavements, Stage II. Skid and Abrasion Resistance of Concrete with Manufactured Sands. CCAA Research Report, Australia.

[3] Sirivivatnanon, V., and Dumitru, I. 2012. "Specifying Manufactured Sands for Concrete Applications." Presented at CMIC 12 Construction Materials Industry 
Conference, Melbourne, Australia.

[4] RMS (Roads and Maritime Services). 2010. $Q A$ Specification R83, Jointed Concrete Base, Revision 8. 2nd ed. New South Wales: RMS.

[5] Weller, D. E., and Maynard, D. P. 1970. The Influence of Materials and Mix Design on the Skid Resistance Value and Texture Depth in Concrete. RRL Report LR334, UK.

[6] AASHTO (American Association of State Highway and Transportation Officials). 1976. Guidelines for Skid Resistance Pavement Design. Washington, D.C.: AASHTO.

[7] NCHRP (National Cooperative Highway Research Program). 2009. Guide for Pavement Friction, Project 01-43. Washington, D.C.: NCHRP.

[8] Nissoux, J. L. 1977. "French Methods and Experiments for Achieving High Skid Resistance on New Pavements." Presented at Colloquium on Surface Characteristic of Concrete Pavements, London, UK.

[9] Weller, D. E. 1970. A Review of the Low-Speed Skidding Resistance of a Number of Concrete Roads Containing Various Aggregates. RRL Report LR335, UK.

[10] Flintsch, G. W., De Leon, E., McGhee, K. K., and Al-Qadi, I. L. 2003. "Pavement Surface Macrotexture Measurement and Application." Presented at TRB (Transportation Research Board) 2003 Annual Meeting, Washington, D.C., USA.

[11] Dahir, S. H., and Henry, J. J. 1978. Alternatives for the
Optimization of Aggregates and Pavement Properties Related to Friction and Wear Resistance. Washington, D.C.: Federal Highway Administration.

[12] Standards Australia. 2009. Australian Standard Methods for Sampling and Testing Aggregates, AS 1141.11.1: Particle Size Distribution-Sieving Method. Sydney: Standards Australia.

[13] Dumitru, I., and Crabb, R. 2000. "Assessment of Aggregate Suitability for Use in Asphaltic Concrete Using Methylene Blue Adsorption Value." Presented at the 1st International Conference "World of Asphalt", Sydney, Australia.

[14] Rached, M. M., and Fowler, D. W. 2012. "Identifying Fine Aggregates Prone to Polishing in PPC Pavements." In Proceedings of the 10th International Conference on Concrete Pavements: Sustainable Solutions to Global Transportation Needs, 1138-51.

[15] Kaya, T., Nagahara, Y., and Yamamoto, H. 2012. "Research on Durability Level of Rock-Derived Micro-fine Particles in Sand for Concrete." Architectural Institute of Japan AIJ Journal of Technology and Design 16 (32): 5-10.

[16] Dumitru, I., Zdrilic, T., and Smorchevsky, G. 1999. "The Use of Manufactured Quarry Fines in Concrete." Presented at the 7th Annual Symposium "Aggregates, Asphalt Concrete, Bases and Fines", ICAR (International Centre for Aggregates Research), Austin, USA . 